\title{
Determination of Some Physical Fitness and Body Composition Characteristics of Young Bocce Players in Turkish National Team
}

\author{
Mutlu Türkmen ${ }^{1,2}$, Ali Özkan' ${ }^{1}$,Taner Bozkuş', Murat Kul' \\ 'Bartın University, School of Physical Education and Sports, Bartin, Turkey, ${ }^{2}$ Turkish Bocce Bowling and Darts Federation, Ankara, Turkey
}

\begin{abstract}
Bocce is gaining popularity throughout the world and is a game that is dominated by aerobic and anaerobic power-capacity, endurance, and strength and body composition. These are all important factors in order to reach a successful performance in Bocce. The purpose of this study was to determine some physical fitness and body composition characteristics of young Bocce players in Turkish national team. A total of 26 six (14 female age $21.00 \pm 8.47$ and 12 male age 19.58 \pm 3.34 ) Bocce players from National Team of Turkey participated in this study voluntarily. Subjects' height, body weight, body mass index and body fat percentage were measured. Body fat percentage was determined by Yuhasz formula, and isometric dynamometer was used in order to determine knee, back, grip strength. The sit and reach test was used for the determination of flexibility. Results indicated that Bocce players have normal body mass index and body fat percentage and ectomorphy-mesomorphy properties. Results of the isometric knee, back, right-left grip strength values of Bocce players was $77.54 \pm 24.8 \mathrm{~kg}$, $90.54 \pm 26.85 \mathrm{~kg}$ and $36.10 \pm 9.91-34.27 \pm 10.08$ respectively and have normal flexibility (32.5 \pm 5.86$)$. As a conclusion, the findings of the present study indicated that Bocce players have almost average body fat percentage, isometric strength and flexibility function.
\end{abstract}

Key words: physical fitness characteristics, body composition, bocce players, strength, endurance, flexibility

\section{Introduction}

The physiological demands of Bocce require players to be competent in several aspects of fitness, which include aerobic and anaerobic power, muscle strength, balance, flexibility and body composition (muscle fiber distribution, muscle cross sectional area, leg volume-mass, etc). These fitness components often vary with the individual player, the positional role in the team and the team's style of play. In addition body composition, aerobic and anaerobic performance, muscle strength, power, and speed are important physiological characteristics of Bocce players in order to perform in a Bocce game. Therefore it is clear that aerobic-anaerobic performance, balance and muscular strength play a major role in optimal performance in Bocce. In particular, anaerobic performance and muscle strength of the lower limbs are significantly associated with vertical jump height and sprinting performance (Wisloff, Castagna, Helgerud, Jones, \& Hoff, 2004). Previous investigators have shown significant differences in muscle strength, anaerobic performance, sprint performance and vertical jump between team players of different ages (Çakır, Sönmez, \& Yılmaz, 2009), muscle fiber distribution (Esbjornsson, Sylven, Holm, \& Jansson, 1993), muscle cross sectional area (Rosene, Fogarty, \& Mahaffey, 2001), leg volume, leg mass (Chelly et al., 2010), intensity of training, levels of competition (Hencken \& White, 2006) and Bocce teams of different divisions (Wisloff et al., 2004; Gissis et al., 2006).

Muscle strength can be defined as the amount of force a muscle group can exert against a resistance in one maximal effort and is closely related with anaerobic performance (Çakır et al., 2009). Muscle strength of the lower limbs in particular

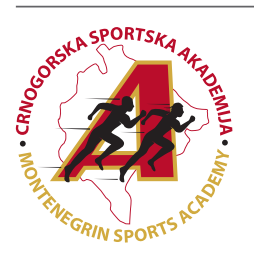

Correspondence:

A. Ozkan

Bartın University, School of Physical Education and Sports, Department of Coaching, Agdaci Kampusu, 74100, Bartin, Turkey

E-mail: ali_ozkan1@hotmail.com 
is of concern in Bocce because during relevant Bocce activities lower limb muscles must generate high forces for dribbling, turning and change of pace (Bradic, Bradic, Pasalic, \& Markovic, 2009).

Body composition (body size and somatotype) is another factor that is generally accepted to have a great influence on athletic performance (Reilly, Bangsbo, \& Franks, 2000). Specifically body fat and fat free mass have been accepted as a crucial component of aerobic-anaerobic performance (Mayhew, Hancock, Rollison, Ball, \& Bowen, 2001), strength and sprint performance (Dowson, Nevill, Lakomy, Nevill, \& Hazeldine, 1998). For instance, Mayhew et al. (2001) reported that body composition component was one of the major factors explaining the anaerobic power and sprint performance.

Sprint performance is another fundamental activity for many sports and consists of a number of components such as the start, acceleration and maximum speed phases. It is known that sprinting requires high force production. Previous research has identified force production capabilities of legs to be a key component in sprinting (Kin İşler, Arıburun, Özkan, Aytar, \& Tandoğan, 2008).

Bocce has many similarities with any other sports disciplines. It can be played by individuals, pairs, or teams of three. It is gaining popularity throughout the world and is a game that is dominated by aerobic and anaerobic power-capacity, endurance, strength, flexibility, and balance and body composition. These are important factors for successful Bocce performance. Bocce, which is known as "Boules" or "Petanque" in French and "Bowls" in English, has been a very popular sport in Turkey during last 10 years after the establishment of the national federation in 2005. It has been adopted as one of the school sports in 2013, and got popularity in schools all around Turkey. Bocce is a very typical sport, as it includes both individual and team competitions, and has traditional strategic games played against opponent teams, and fast flowing, endurance and strength demanding disciplines played against time (Turkmen, 2011; Turkmen, Bozkus, \& Altintas, 2013). Thus, it would represent both individual and team sports and require both mental and physical competencies. Therefore the findings of this study would normally be applicable to many other similar sport disciplines. To date, no studies have been reported that specifically investigated the relationship between aerobic, anaerobic performance, strength, balance, locomotor capacity and speed of action. The purpose of the present study was to investigate some physical fitness and body composition characteristics of young Bocce players representing Turkish national Bocce team, which is the first study so far on Bocce players; therefore it will have an important effect on scientific studies focusing on Bocce in near future.

\section{Methods}

\section{Subjects and Experimental Approach}

A total of twenty six (14 female age $21.00 \pm 8.47$ and 12 male age 19.58 \pm 3.34 ) Bocce players who were selected for junior and espoirs national teams in 2016, participated in this study voluntarily. The subjects were informed about the possible risks and benefits of the study and gave their informed consent to participate in this study. The study was conducted over a five days period, during which the players did not participate in any other training or matches. Subjects' height, body weight, body mass index and body fat percentage were determined. Body fat percentage was determined by Yuhasz formula. Isometric Dynamometer was used for the determination of knee, back, grip strength. The sit and reach test was used for the determination of flexibility.

\section{Procedures}

\section{Anthropometric Measurements}

Subjects reported to the laboratory at 8:00 am First, body height $(\mathrm{cm})$, body mass $(\mathrm{kg})$, and percentage of body fat $(\mathrm{PBF})$ measurements were taken for each subject. The body height of the Bocce players was measured by a stadiometer with an accuracy of $\pm 1 \mathrm{~cm}$ (SECA, Germany), and while electronic scales (Tanita BC 418, Japan) accurate to within $0.1 \mathrm{~kg}$ were used to measure body mass and percentage of body fat (Lohman, Slaughter, Boileau, Bunt, \& Lussier, 1984). Skinfold thickness was measured with a Holtain skinfold caliper (Hotain, UK) which applied a pressure of $10 \mathrm{~g} / \mathrm{mm}^{2}$ with an accuracy of $\pm 2 \mathrm{~mm}$. Gulick anthropometric tape (Holtain, UK) with an accuracy of $\pm 1 \mathrm{~mm}$ was used to measure the circumference of extremities. Diametric measurements were determined by Harpenden callipers (Holtain, UK) with an accuracy of \pm 1 $\mathrm{mm}$. The Bocce players' somatotypes were then calculated using the Heath-Carter formula.

\section{Vertical Jump Measurements}

Vertical jump performance was measured using a portable force platform (Newtest, Finland). Players performed countermovement (CMJ) and squat jumps (SJ) according to the protocol described by Bosco, Luhtanen, \& Komi (1983). Before testing, the players performed self-administered submaximal CMJs and SJ (2-3 repetitions) as a practice and specific additional warm-up. They were asked to keep their hands on their hips to prevent any influence of arm movements on the vertical jumps and to avoid coordination as a confounding variable in the assessment of the leg extensors (Bosco et al., 1995). Each subject performed 3 maximal CMJs and SJs, with approximately 2 minutes' recovery in between. Players were asked to jump as high as possible; the best score was recorded in centimeters (Bosco et al., 1995).

\section{Flexibility measurement}

Flexibility was evaluated by the sit and reach test which is the most common flexibility test used in health related fitness test batteries. The subjects sat with their feet approximately hip-width against the testing box. They kept their knees extended and placed the right hand over the left, and slowly reached forward as far as they could by sliding their hands along the measuring board. Reaches short of the toes were recorded as negative forward reach scores, and reaches beyond the toes were recorded as positive forward reach scores in centimetre to the nearest $0.5 \mathrm{~cm}$ using the scale on the box (Kayıhan, Ersöz, \& Özkan, 2013).

\section{Strength measurement}

Isometric Dynamometer was used for the determination of knee, back, grip strength. Muscular strength was assessed using a Takei strength dynamometer (Takei Scientific Instruments, Tokyo, Japan).

\section{Statistical analyses}

Means and standard deviations are given as descriptive statistics and the relationship among body composition, isometric strength and vertical jump performance in Bocce play- 
ers was evaluated by Pearson product Moment Correlation analysis. All analysis were executed in SPSS for Windows version 17.0 and the statistical significance was set at $\mathrm{p}<0.05$.

\section{Results}

The body composition, anaerobic performance (vertical jump) and isometric strength measurements of the Bocce players in the study are presented in Tables 1,2, and 3; and the correlations are presented in Table 4, 5, and 6 respectively.

As can be seen from Table 1, Bocce players have normal body mass index, body fat percentage, and ectomorphy-mesomorphy properties.

Table 1. Body Composition of Bocce Players (mean $\pm s d$ )

\begin{tabular}{|c|c|c|c|c|c|c|c|}
\hline & $\begin{array}{l}\text { Body Height } \\
\quad(\mathrm{cm})\end{array}$ & $\begin{array}{l}\text { Body Mass } \\
\quad(\mathrm{kg})\end{array}$ & $\begin{array}{l}\text { Body Fat } \\
(\%)\end{array}$ & BMI & Endo & Meso & Ecto \\
\hline $\begin{array}{l}\text { Players } \\
(n=26)\end{array}$ & $168.9 \pm 7.40$ & $61.53 \pm 10.40$ & $15.07 \pm 5.7$ & $21.45 \pm 2.65$ & $1.52 \pm 1.32$ & $2.90 \pm 1.42$ & $4.57 \pm 1.21$ \\
\hline $\begin{array}{c}\text { Female } \\
(n=14)\end{array}$ & $164.15 \pm 5.53$ & $54.95 \pm 6.52$ & $18.60 \pm 4.33$ & $20.24 \pm 2.07$ & $1.78 \pm 1.12$ & $2.74 \pm 1.32$ & $3.65 \pm 1.40$ \\
\hline $\begin{array}{l}\text { Male } \\
(n=12)\end{array}$ & $174.55 \pm 4.98$ & $61.53 \pm 10.40$ & $10.91 \pm 4.15$ & $22.89 \pm 2.61$ & $1.42 \pm 1.58$ & $3.25 \pm 1.56$ & $4.78 \pm 1.36$ \\
\hline
\end{tabular}

Both Table 2 and 3 conveys that Bocce players have average anaerobic, flexibility, and isometric strength performances.
According to Table 4, the Pearson Product Moment Correlation analyses indicated that significant correlations existed

Table 2. Anaerobic Performance and Flexibility Performance Values of Bocce Players (mean $\pm s d$ )

\begin{tabular}{cccccccc}
\hline & \multicolumn{3}{c}{ Counter Movement Jump } & \multicolumn{3}{c}{ Squat Jump } & \multicolumn{2}{c}{ Flexibility } \\
\cline { 2 - 8 } & $\begin{array}{c}\text { Absolute } \\
(\mathrm{CMJ}) \\
(\mathrm{Watt})\end{array}$ & $\begin{array}{c}\text { Relative } \\
(\mathrm{RCMJ}) \\
\left(\mathrm{W} \cdot \mathrm{kg}^{-1}\right)\end{array}$ & $\begin{array}{c}\text { Jump Height } \\
(\mathrm{CJH}) \\
(\mathrm{cm})\end{array}$ & $\begin{array}{c}\text { Absolute } \\
(\mathrm{SJ}) \\
(\text { Watt })\end{array}$ & $\begin{array}{c}\text { Relative } \\
(\mathrm{RSJ}) \\
\left(\mathrm{W} \cdot \mathrm{kg}^{-1}\right)\end{array}$ & $\begin{array}{c}\text { Jump Height } \\
(\mathrm{SJH}) \\
(\mathrm{cm})\end{array}$ & $\begin{array}{c}\text { Sit and } \\
\text { Reach } \\
(\mathrm{cm})\end{array}$ \\
\hline $\begin{array}{c}\text { Players } \\
(\mathrm{n}=26)\end{array}$ & $794.8 \pm 117.5$ & $13.2 \pm 0.6$ & $36.2 \pm 2.3$ & $742.8 \pm 141.2$ & $12.3 \pm 0.4$ & $33.1 \pm 2.37$ & $32.75 \pm 6.01$ \\
\hline
\end{tabular}

CMJ: Counter movement jump, RCMJ: Relative counter movement jump, SJ: Suquat jump, RSJ: Relative squat jump

between body composition and anaerobic performance values. minant role in anaerobic performance in Turkish national Therefore, it can be said that body composition plays a deter- Bocce players. On the other hand, body composition, anaero-

Table 3. Isometric Strength Performance of Bocce Players (mean \pm sd)

\begin{tabular}{ccccccc}
\hline & \multicolumn{5}{c}{ Isometric Strength } \\
\cline { 2 - 7 } & Back & Knee & Right Grip & Left Grip & Total & Relative \\
\hline $\begin{array}{c}\text { Players } \\
(\mathrm{n}=26)\end{array}$ & $90.54 \pm 26.85$ & $77.54 \pm 24.81$ & $36.10 \pm 9.91$ & $34.27 \pm 10.08$ & $238.46 \pm 85.94$ & $3.84 \pm 0.81$ \\
\hline
\end{tabular}

bic and strength performance had no significant relation with flexibility $(\mathrm{p}>0.05)$.
According to Table 5, the Pearson Product Moment Correlation analyses indicated that significant correlations existed

Table 4. Correlations between Body Composition and Flexibility with Anaerobic Performance

\begin{tabular}{|c|c|c|c|c|c|c|c|}
\hline & CMJ & RCMJ & $\mathrm{CJH}$ & SJ & RSJ & SJH & Flexibility \\
\hline Body Weight & $.635^{*}$ & $.512^{* *}$ & NS & NS & $.733^{* *}$ & $-.597^{* *}$ & NS \\
\hline Body Mass & $.612^{* *}$ & $.540^{*}$ & NS & NS & $.655^{* *}$ & $-.539 * *$ & NS \\
\hline Body Fat & NS & $.512^{*}$ & $.878^{* *}$ & NS & $-.575^{*}$ & $-.670^{*}$ & NS \\
\hline BMI & $.512^{*}$ & NS & NS & NS & NS & $-.586^{*}$ & NS \\
\hline Endomorfism & $.878^{* *}$ & NS & NS & NS & NS & NS & NS \\
\hline Mesomorfism & NS & NS & NS & NS & NS & NS & NS \\
\hline Ectomorfism & NS & NS & NS & NS & NS & NS & NS \\
\hline
\end{tabular}

${ }^{*} p<0.05 ;{ }^{* *} p<0.01$

between isometric strength and body composition. Therefore, it is concluded that body composition is a crucial component in strength performance of Bocce players.

According to Table 6, the Pearson Product Moment Cor- 
relation analyses indicated that significant correlations existed between anaerobic performance and isometric strength.

On the other hand, none of the measurements of anaerobic and strength performance values were significantly related to

Table 5. Correlations between Body Composition and Isometric Strength Performance

\begin{tabular}{lccccccc}
\hline Strength & $\begin{array}{c}\text { Body Height } \\
(\mathrm{cm})\end{array}$ & $\begin{array}{c}\text { Body Mass } \\
(\mathrm{kg})\end{array}$ & $\begin{array}{c}\text { Body Fat } \\
(\%)\end{array}$ & BMI & Endomorf & Mesomorf & Ectomorf \\
\hline Back & $.433^{*}$ & $.713^{* *}$ & NS & $.610^{* *}$ & $-.733^{* *}$ & $-.597^{* *}$ & NS \\
Knee & $.515^{*}$ & $.740^{* *}$ & NS & $.577^{* *}$ & $-.655^{* *}$ & $-.539^{* *}$ & NS \\
Right Grip & $.775^{* *}$ & $.829^{*}$ & $-.448^{*}$ & $.631^{* *}$ & $-.575^{*}$ & $-.670^{*}$ & NS \\
Left Grip & $.605^{*}$ & $.719^{* *}$ & $-.524^{* *}$ & $.658^{* *}$ & NS & $-.586^{*}$ & NS \\
Total & $.803^{*}$ & $.597^{* *}$ & $-.407^{*}$ & $.661^{* *}$ & NS & NS & NS \\
Relative & NS & NS & $-.440^{* *}$ & NS & NS & NS & NS \\
\hline
\end{tabular}

${ }^{*} \mathrm{p}<0.05-{ }^{* *} \mathrm{p}<0.01$

flexibility ( $\mathrm{p}>0.05)$. Therefore, it is concluded that strength is a crucial component in anaerobic performance of bocce players, but flexibility has no significant relation with anaerobic performance

Table 6. Correlations between Anaerobic Performance and Flexibility with Isometric Strength

\begin{tabular}{|c|c|c|c|c|c|c|c|}
\hline Strength & CMJ & $\mathrm{RCMJ}$ & $\mathrm{CJH}$ & SJ & RSJ & SJH & Flexibility \\
\hline Back & $.540 *$ & $.450^{*}$ & $.760^{*}$ & NS & $.948^{*}$ & NS & NS \\
\hline Knee & $.650^{* *}$ & $.550^{*}$ & NS & NS & NS & NS & NS \\
\hline Right Grip & $.590^{*}$ & $.620^{* *}$ & $.913^{* *}$ & NS & $.813^{* *}$ & NS & NS \\
\hline Left Grip & $.680^{*}$ & NS & NS & NS & NS & NS & NS \\
\hline Total & NS & NS & NS & NS & NS & NS & NS \\
\hline Relative & NS & NS & NS & NS & NS & NS & NS \\
\hline
\end{tabular}

${ }^{*} \mathrm{p}<0.05 ;{ }^{* *} \mathrm{p}<0.01$

\section{Discussion}

The major finding of the present study is the existence of significant relation between body composition, anaerobic power, flexibility and isometric strength. This result is consistent with the results of previous studies. For instance Pyne, Duthie, Saunders, Petersen and Portus (2006) highlighted anthropometric measures of upper-body power, arm length and static jump as good correlates of peak ball speed in junior and senior fast bowlers. And Pyne et al. (2006) also have outlined the role of lower-body power as a partial predictor of ball release speed in senior bowlers, while Portus, Mason, Elliot, Pfitzer and Done (2004) have reported front knee bracing action and higher braking forces were related to higher ball speeds, which might be accounted for faster run up speeds. Taken in context of the current results, these findings highlight the importance of physical conditioning to improve peak running and potentially run-up speed. Moreover, training should also include the ability to tolerate increased bracing forces and transfer momentum from front-foot contact, through the trunk to the ball, to improve bowling performance (either throughout a spell or on specific balls). Consequently, as a player improves speed and strength it might result in a more efficient delivery stride and increase optimal speed. However, it must be noted that while an increased run-up speed might be of some benefit, there will be a point where increased speed results in a loss of control (Duffield, Carney, \& Karppinen, 2009). On the other hand, Baker and Nance (1999) investigated the relationship between strength and power in rugby players and determined a strong positive correlation between maximum strength and maximum power. In another study Thorland, Johnson, Cisar,
Housh and Tharp (1987) determined significant strong correlation between isokinetic knee strength and anaerobic power and capacity of female sprinter and middle distance runners. According to Mayhew et al. (2001) leg extension strength strongly predicted anaerobic power in healthy college students; and Arslan (2005) also found that peak and mean power of university students who exercise regularly were correlated with explosive leg strength. As known muscular strength is one of the important factor that has a major role in anaerobic performance because with increased muscular strength the ability of muscles to generate muscular contraction in short-term high intensity activity also increases.

Newman, Tarpenning and Marino (2004) found that concentric isokinetic knee extension and flexion strength measures were significantly correlated to single-sprint performance in football players. On the other hand, Cronin and Hansen (2005) determined no association between knee flexion and extension strength and single-sprint performance that was determined over $5 \mathrm{~m}, 10 \mathrm{~m}$ and $30 \mathrm{~m}$ in rugby players. A plausible explanation for the lack of association between isokinetic knee strength and single-sprint performance in the present study might be due to subjects' characteristics. Bocce is a developing sport branch in Turkey and is played at the league level. Hence, the subjects of the present study are young players with a short background and low-level training experience. Having low training experience may be one of the reasons for the lack of association between body composition and physical fitness. Another possible explanation for the lack of association may be the different energy systems that each measure demands. To conclude, the findings of the present study indicated that 
body composition play a determinant role in anaerobic performance, strength and flexibility performance in Bocce players. In addition, strength performance was found to be an important factor in anaerobic performance of Bocce players.

\section{Acknowledgements}

The authors would like to thank young Bocce players in Turkish national team who voluntarily participated in this research.

\section{Conflict of Interest}

The authors declare there are no conflict of interest.

Received: 10 August 2017| Accepted: 18 September 2017

\section{References}

Arslan, C. (2005). Relationship between the 30-second Wingate test and characteristics of isometric and explosive leg strength in young subjects. Journal of Strength and Conditioning Research, 19(3), 658-666.

Baker, D. \& Nance, S. (1999). The relation between running speed and measures of strength and power in professional rugby league players. Journal of Strength and Conditioning Research, 13(3), 230-235.

Bosco, C., Luhtanen, P., \& Komi, P.V. (1983). A simple method for measurement of mechanical power in jumping. European Journal of Applied Physiology, 50, 273-282.

Bosco, C., Belli, A., Astrua, M., Tihanyi, J., Pozzo, R., Kellis, S., Tsarpela, O., Foti, C., Manno, R., \& Tranquilli, C. (1995). A dynamometer for evaluation of dynamic muscle work. European Journal of Applied Physiology and Occupational Physiology, 70, 379-86.

Bradic, A., Bradic, J., Pasalic, E., \& Markovic, G. (2009). Isokinetic leg strength profile of elite male basketball players. Journal of Strength and Conditioning Research, 23(4), 1332-1337.

Çakır, A.H., Sönmez, A.G., \& Yilmaz, I. (2009). The relationship between isokinetic strength of knee extensors/flexors, jumping and anaerobic performance. Isokinetics and Exercise Science, 17, 1-5.

Chelly, M.S., Cherif, N., Amar, M.B., Hermassi, S., Fathloun, M., Bouhlel, E., Tabaka, Z. \& Shephard, R.J. (2010). Relationships of peak leg power, 1 maximal repetition half back squat, and leg muscle volume to $5-\mathrm{m}$ sprint performance of junior soccer players. Journal of Strength and Conditioning Research, 24(1), 266-271.

Cronin, B.J., \& Hansen, T.K. (2005). Strength and power predictors of sports speed. Journal of Strength and Conditioning Research, 19(2), 349-357.

Dowson, M.N., Nevill, M.E., Lakomy, H.K.A., Nevill, A.M., \& Hazeldine, R.J. (1998). Modelling the relationship between isokinetic muscle strength and sprint running performance. Journal of Sport Sciences, 16, 257-265.

Duffield, R., Carney, M., \& Karppinen, S. (2009). Physiological responses and bowling performance during repeated spells of medium-fast bowling. Journal of Sports Sciences, 27(1), 27-35.

Esbjornsson, M., Sylven, C., Holm I., \& Jansson, E. (1993). Fast twitch fibers may predict anaerobic performance in both females and males. International Journal of Sports Medicine, 14(5), 263-268.
Gissis, I., Papadopoulos, C., Kalapotharakos, V.I., Sotiropoulos, A., Komsis, G., \& Manolopoulos, E. (2006). Strength and speed characteristics of elite, subelite and recreational young soccer players. Research in Sports Medicine, 14, 205-214.

Hencken, C. \& White, C. (2006). Anthropometric assessment of premiership soccer players in relation to playing position. European Journal of Sport Science, 6(4), 205-211.

Kayıhan, G., Ersöz, G., \& Özkan, A. (2013). The relationship between selected physical-physiological parameters and efficiency of pistol shooting. Policing: An International Journal of Police Strategies \& Management, 36(4), 819-832.

Kin İşler, A., Arıburun, B., Özkan, A., Aytar, A., \& Tandoğan, R. (2008). The relationship between anaerobic performance, muscle strength and sprint ability in American football players. Isokinetic and Exercise Science, 16, 87-92.

Lohman, T.G., Slaughter, M.H., Boileau, R.A., Bunt, J., \& Lussier, L. (1984) Bone mineral measurements and their relation to body density in children, youth and adults. Human Biology, 56, 667-679.

Mayhew, J.L., Hancock, K., Rollison, L., Ball, T.E., \& Bowen, J.C. (2001). Contributions of strength and body composition to the gender difference in anaerobic power. Journal of Sports Medicine and Physical Fitness, 41, 33-38.

Newman, M.A., Tarpenning, K.M., \& Marino, F.E. (2004). Relationships between isokinetic knee strength, single sprint performance and repeated-sprint ability in football players. Journal of Strength and Conditioning Research, 18(4), 867-872.

Reilly, T., Bangsbo, J., \& Franks, A. (2000). Anthropometric and physiological predispositions for elite soccer. Journal of Sports Sciences, 18, 669-683.

Rosene, J.M., Fogarty, T.D., \& Mahaffey, B.L. (2001). Isokinetic hamstrings:quadriceps ratios in intercollegiate athletes. Journal of Athletic Training, 36(4), 378-383.

Pyne, D.B., Duthie, G.M., Saunders, P.U., Petersen, C.A., \& Portus, M.R. (2006). Anthropometric and strength correlates of fast bowling in junior and senior cricketers. Journal of Strength and Conditioning Research, 20, 620626.

Portus, M.R., Mason, B.R., Elliot, B.C., Pfitzer, M.C., \& Done, R.P. (2004). Technique factors related to ball release speed and trunk injuries in high performance crickets fast bowlers. Sports Biomechanics, 3, 263-283.

Thorland, W.G., Johnson, G.O., Cisar, C.J., Housh, T.J., \& Tharp, G.D. (1987) Strength and anaerobic responses of elite young female sprint and distance runners, Medicine and Science in Sport and Exercise, 19(1), 56-61.

Turkmen, M. (2011). Bocce: Bowls, Petanque, Raffa and Boules, Definitions, History, and Rules, Ankara: Neyir Publication, (in Turkish).

Turkmen, M., Bozkus, T., \& Altintas A. (2013). The relationship between motivation orientations and competitive anxiety in bocce players: does gender make a difference. Psychology and Behavioral Sciences, 2(4), 162-168, doi: 10.11648/j.pbs.20130204.12

Wisloff, U., Castagna, C., Helgerud, J., Jones, R., \& Hoff, J. (2004). Strong correlation ofmaximal squat strength with sprint performance and vertical jump height in elite soccer players. British Journal of Sports Medicine, 38, 285-288. 